\title{
Simone de Beauvoir bajo la dictadura franquista: las traducciones al catalán
}

\author{
Pilar Godayol \\ Universitat de Vic-Universitat Central de Catalunya \\ pgodayol@uvic.cat
}

\begin{abstract}
Resumen: Simone de Beauvoir fue traducida por primera vez al catalán durante el franquismo. El objetivo de este artículo es investigar la censura institucional que experimentaron, en la segunda mitad de la década de los sesenta del siglo pasado, seis obras de Beauvoir para ser publicadas en catalán, desde que las editoriales solicitaron los permisos hasta conseguir las autorizaciones. Después de contextualizar brevemente las traducciones, el artículo se centra en el estudio de los seis expedientes de censura, que nos permitirá averiguar cómo reaccionó la dictadura ante la posibilidad de traducir obras de Beauvoir (considerada por el régimen autora peligrosa por filocomunista, feminista y atea), quiénes fueron sus censores, qué observaciones formularon y, finalmente, qué tipo de castigos intelectuales les practicaron.
\end{abstract}

Palabras clave: historia de la traducción; traducción al catalán; censura; feminismo; Simone de Beauvoir.

\begin{abstract}
Simone de Beauvoir was translated into Catalan during Franco's dictatorship. This article investigates the institutional censorship applied, in the second half of the 1960s, to six works by Simone de Beauvoir prior to their publication in Catalan, from the publishers' initial applications for permits till final authorization. After a brief contextualization of the translations, the article centers on the study of the six reports of the censors. This study reveals how the Francoist dictatorship reacted to the possibility of translating into Catalan works by Simone de Beauvoir, considered by the regime to be a 'dangerous' writer, an atheist and feminist with communist tendencies. It also gives details of the censors involved, of their observations and, finally, of the type of intellectual penalties imposed.
\end{abstract}

Keywords: history of translation; translation into Catalan; censorship; feminism; Simone de Beauvoir.

》 Godayol, Pilar. 2015. "Simone de Beauvoir bajo la dictadura franquista: las traducciones al catalán". Quaderns de Filologia: Estudis Literaris XX: 17-34. doi: 10.7203 /qdfed.20.7526 



\section{Introducción: censura y traducción durante la dictadura franquista (1939-1975)}

La dictadura franquista en España conllevó durante años una obstrucción acérrima del funcionamiento de las empresas editoriales del país. Cualquier texto impreso tenía que pasar obligatoriamente el trámite de la censura previa. Amparados por todo tipo de leyes, el cuerpo de censores del estado trabajaba duramente para controlar la comunicación social. Si durante este período el libro catalán sufrió las mismas limitaciones que el libro en castellano (es decir, una implacable censura de los textos contrarios a la ideología del régimen), obviamente se le sumaron las restricciones de contenido nacional e identitario, que acabaron privilegiando los libros más minoritarios, como los religiosos, las monografías locales o la poesía. Durante las primeras décadas del franquismo las traducciones al catalán fueron totalmente prohibidas, con unas pocas excepciones ${ }^{1}$.

El cambio llegó en 1962, cuando asumió el cargo de ministro de Información y Turismo Manuel Fraga Iribarne. La tenue apertura de su ministerio (MIT) aportó aires de modernidad a la industria editorial, adaptándose a los nuevos tiempos sociales y políticos que vivían Europa y Norteamérica. El nuevo contexto propició que el sector editorial catalán viviera unos años de expansión entre 1962 y 1970. Fue en ese momento cuando se promulgó la Ley de Prensa y de Imprenta, del 18 de marzo de 1966, y se invalidó la anterior, del 29 de abril de 1938; es decir, se pasó de la censura previa obligatoria de los originales a la consulta voluntaria. Fuese por razones políticas y económicas intrínsecas, fuese para demostrar a Occidente que el régimen dictatorial español caminaba hacia cierta apertura ideológica, a partir de 1962 las autoridades

\footnotetext{
* Este artículo se enmarca en las actividades del grupo de investigación consolidado "Grup d'Estudis de Gènere: Traducció, Literatura, Historia i Comunicació" (GETLIHC) (2014, SGR 62) de la Universitat de Vic-Universitat Central de Catalunya y del proyecto $\mathrm{I}+\mathrm{D}+\mathrm{i}$ «Traducción y censura: género e ideología (1939-2000)», con el número de referencia FFI2014-52989-C2-2-P, financiado por el Ministerio de Economía y Competitividad. Número ORCID de la autora: 0000-0003-2513-5334.E-mail: pgodayol@ uvic.cat.

${ }^{1}$ Para conocer la política censora durante el franquismo, consultar, entre otros, los estudios de Cisquella et al. (2002 [1977]), Abellán (1980), Vallverdú (1987; 2013), Gallofré (1991), Gutiérrez-Lanza (1997), Moret (2002), Llanas (2006), Merino (2008), Vandaele (2010), Cornellà-Detrell (2010; 2013) y Bacardí (2012).
} 
franquistas permitieron las traducciones al catalán, consideradas hasta entonces una vía de modernización y, por lo tanto, temidas y prohibidas. A pesar de todo, hasta 1978 las tuvieron bajo una censura encubierta, lo que el régimen bautizó como consulta voluntaria.

El principal objetivo de este artículo es investigar los expedientes de censura de los seis títulos de Simone de Beauvoir traducidos al catalán en la segunda mitad de la década de los sesenta. Consultados los informes en el Archivo General de la Administración (AGA) de Alcalá de Henares, su estudio nos permitirá abordar las siguientes preguntas: 1. ¿Cómo se posicionó el franquismo, por medio del aparato censor del MIT, ante las solicitudes de traducciones al catalán de Simone de Beauvoir, etiquetada por el régimen de autora peligrosa?; 2. ¿Qué perfil tenían los censores encargados de redactar sus informes?; 3. ¿Qué argumentos sostuvieron?; y 4. ¿Qué tipo de tachaduras, prohibiciones y dilaciones temporales practicaron?

\section{Las traducciones al catalán de Simone de Beauvoir de los años sesenta}

Simone de Beauvoir se versionó por primera vez al catalán a finales de los años sesenta. Su aterrizaje coincidió con un boom editorial, fruto de un contexto histórico y social que alimentó el interés por su obra política, existencialista y feminista. Después de tres décadas sin publicar Beauvoir en lengua catalana, en 2002 aparecía la traducción de $L a$ dona trencada (La femme rompue), de Marta Pessarrodona, y, en 2008, se reavivaba el interés por la autora con la celebración del centenario de su nacimiento (Godayol, 2013b).

Las seis primeras traducciones de Beauvoir al catalán son todas de la segunda mitad de la década de los sesenta. En cuatro años, entre 1966 y 1969, se publicaron los siguientes títulos, por orden de aparición editorial: Una mort molt dolça (Une mort très douce) (1966), El pensament polític de la dreta (Privilèges) (febrero 1968), Les belles imatges (Les belles images) (marzo 1968), El segon sexe (Le deuxième sexe) (junio 1968), Per una moral de l'ambigüitat (Pour une morale de l'ambiguité) (julio 1968) y La mesura de l'home (Pyrrhus et Cinéas) (1969).

En 1966 apareció la primera traducción de Beauvoir a la lengua catalana: el narrador y político Ramon Xuriguera versionó Una mort molt 
dolça. En el prólogo Xuriguera describe a Beauvoir como "uno de los valores más destacados de la actual literatura francesa" (1966: 7). Dos años después, en 1968, llegaron cuatro traducciones más. Fue el año Beauvoir en Cataluña. De las cuatro, un par fueron a cargo del jurista y escritor Jordi Solé-Tura: en febrero El pensament politic de la dreta (editada en París en 1955) y en julio Per una moral de l'ambigüitat (editada en París en 1947), las dos para la colección de "Llibres a l'Abast", de Edicions 62. En marzo de 1968 Joan Oliver trasladó Les belles imatges a la colección "A Tot Vent" de la editorial Aymà, que él dirigía. Meses después de las traducciones de Solé-Tura y de Oliver, en junio de 1968, llegaba el esperado El segon sexe, en traducción de Hermínia Grau y Carme Vilaginés y con una introducción de la escritora Maria Aurèlia Capmany. Un año y un mes después, en julio de 1969, en la colección "Llibres a l'Abast", se publicaba el ensayo La mesura de l’home, en versión del poeta Miquel Martí i Pol.

En la revista Serra d'Or, en julio de 1968, Joan Triadú escribió un artículo en que justificaba el boom traductor de los sesenta por el hecho de que era indispensable recuperar con rapidez "una generación sin novela traducida" (1968: 39). También se fijaba en que, en cinco o seis años, habían aparecido más de un centenar de títulos "a cargo de escritores competentes, a menudo, o de buenos traductores" (1968: 39). Hermínia Grau, Miquel Martí i Pol, Joan Oliver, Jordi Solé-Tura, Carme Vilaginés y Ramon Xurriguera (Bacardí \& Godayol, 2011), los traductores catalanes de Beauvoir de esta época, responden a las categorías de Triadú. La mayoría eran escritores reputados de la literatura catalana, un perfil recurrente durante unos años en los cuales, con la liberalización de la censura franquista, gran parte de la intelectualidad compaginaba las dos tareas, a menudo por cuestiones económicas.

\section{Las traducciones de Simone de Beauvoir bajo sospecha: censores, informes, autorizaciones, retenciones y silencios administrativos}

En el AGA se pueden consultar los expedientes de censura de las traducciones al catalán de Simone de Beauvoir, publicadas entre 1966 y 1969 por las editoriales Aymà y Edicions 62: por orden de expediente abierto, El segon sexe ("Biblioteca Bàsica de Cultura Contemporània" 
de Edicions 62) $)^{2}$, Una mort molt dolça ("La Mirada" de Aymà) ${ }^{3}$, Per una moral de l'ambigüitat ("Llibres a l'Abast" de Edicions 62) ${ }^{4}$, Pyrrhus $i$ Cineas ("Llibres a l'Abast" de Edicions 62) ${ }^{5}$, El pensament politic de la dreta ("Llibres a l'Abast" de Edicions 62$)^{6}$ y Les belles imatges ("Biblioteca A tot vent" de Aymà) 7 . Teniendo en cuenta que el orden de las fechas del inicio de los expedientes administrativos para obtener la autorización para traducir las obras no se corresponde con el orden de las fechas de publicación finales, porque en algunas ocasiones se retuvieron, denunciaron o prohibieron, hemos optado por dar a conocer los seis casos por orden de presentación de las solicitudes al MIT con el fin de mostrar sus múltiples coyunturas antes de salir a la luz.

Las dos primeras solicitudes para traducir Beauvoir al catalán las presentaron el mismo mes dos editoriales barcelonesas, Edicions 62 y $\mathrm{AC}$-fundada por Armand Carabén y más tarde incorporada a AymàEdicions 62 solicitó el permiso de El segon sexe el 7 de abril de 1965 y AC el de Una mort molt dolça el 30 de abril de 1965, los dos fechados antes de la aprobación de la llamada Ley Fraga de 1966. Por consiguiente, se acogieron a un protocolo de censura diferente de las otras, la Ley de 1938. A las dos primeras traducciones de Beauvoir, se les aplicó la censura previa obligatoria, a diferencia de la consulta voluntaria de originales que se llevó a cabo en las otras cuatro. Cabe considerar que la consulta voluntaria de la Ley Fraga se podía llevar a cabo antes o después de la edición del libro: la primera consistía en presentar una solicitud de autorización antes de empezar la producción de la traducción y del libro, como en la censura previa obligatoria de años anteriores, mientras que la segunda implicaba depositar seis ejemplares ya impresos del libro en los organismos censores para ser revisados, con la condición de que serían autorizados, porque, en caso contrario, la edición completa era secuestrada y retirada.

De los seis títulos traducidos de Beauvoir en los años sesenta, cuatro fueron a iniciativa de Edicions 62, editorial que no pudo escoger entre la primera y la segunda opción. La razón fue que la Ley de 1966 exigía

\footnotetext{
${ }^{2}$ AGA 21-16124, exp. 02681 (1965) y AGA 21-17881, exp. 00648 (1967).

${ }^{3}$ AGA 21-16212, exp. 03340 (1965).

${ }^{4}$ AGA 21-17469, exp. 04753 (1966).

${ }^{5}$ AGA 21-17469, exp. 04754 (1966).

${ }^{6}$ AGA 21-18726, exp. 00974 (1968).

${ }^{7}$ AGA 21-18865, exp. 02813 (1968).
} 
a las editoriales inscribirse en un registro del MIT. Para obtener el número, tenían que facilitar información financiera y de programación. A Edicions 62 se le denegó el preceptivo número de registro y, después de muchas entrevistas y reuniones, lo obtuvo en 1972. En consecuencia, exigió a la editorial continuar solicitando el visto bueno al MIT antes de iniciar cualquier traducción. Asimismo, esto también provocó que Edicions 62 no tuviera casi nunca ningún libro aprobado por silencio administrativo (veremos una excepción a continuación), ni tampoco ningún libro secuestrado.

\subsection{Los dos expedientes de censura de El segon sexe (Le deuxième sexe) $(1965,1967)$}

La primera solicitud de autorización para traducir al catalán que se presentó de Simone de Beauvoir al MIT fue la de El segon sexe. Sin embargo, entregada a trámite en abril de 1965, no llegó a las librerías hasta junio de 1968. La aventura administrativa fue larga y compleja. Con un retraso considerable (diecinueve años después de su publicación en París, dieciséis después de la traducción inglesa y catorce después de la española argentina), El segon sexe llegó en un momento clave para el emergente discurso feminista catalán. Tuvo un embajador y una embajadora de lujo: el editor Josep Maria Castellet, que no paró hasta obtener la autorización para traducirlo, y la escritora Maria Aurèlia Capmany, que lo prologó y que, una vez traducido, difundió sus ideas. Pese a que no fue moneda fácil conducir este proyecto a buen puerto, podemos constatar que se convirtió en uno de los retos editoriales de Edicions 62. En "Censure, féminisme et traduction: Le Deuxième sexe de Simone de Beauvoir en catalan" (Godayol, 2013a), dimos a conocer con detalle los expedientes de censura y la recepción en Cataluña del ensayo feminista de Beauvoir.

En el AGA hay dos expedientes de censura de la traducción catalana de El segon sexe. El primero, de 1965, concluye con la denegación de la solicitud para reproducir el libro en lengua catalana y la subsiguiente denegación del recurso de revisión. El segundo, de 1967, finaliza con la autorización de la traducción definitiva el 20 de junio de 1968. Por lo tanto, la traducción catalana de $E l$ segon sexe vivió dos protocolos de censura diferentes: el primero se rigió por la Ley de 1938 y el segundo por la de 1966. 
Edicions 62 presentó al MIT la solicitud para traducir el clásico feminista de Beauvoir el 7 de abril de 1965. Se pedía un tiraje de 1.500 ejemplares y se calculaba que ocuparía 972 páginas. Como era habitual, se solicitaron los informes de lectura a dos censores ${ }^{8}$. En este caso, por el renombre internacional de la autora, se requirió a dos autoridades incontestables de la iglesia franquista: el padre Saturnino Álvarez Turienzo y el padre Miguel Oromí Inglés. Cuando el MIT les encargó la lectura, Álvarez Turienzo y Oromí acababan de autorizar sin incidencias la traducción catalana de La mística de la feminitat de Betty Friedan y, por lo tanto, no partían de cero por lo que se refiere a lecturas feministas de la época (Godayol, 2014). Sin embargo, el resultado fue totalmente diferente.

Un mes después de entregar el informe favorable de La mística de la feminitat, el 8 de abril de 1965, se solicitó uno de El segon sexe a Álvarez Turienzo (La Mata de Monteagudo, León, 1920), miembro eminente de la orden agustiniana, especializado en obras filosóficas. Pese reconocer la originalidad de Beauvoir, fue implacable. Puso a disposición del MIT su informe desfavorable el 1 de junio de $1965^{9}$.

Con el dictamen negativo de Álvarez Turienzo, al día siguiente, se le encargó otro informe al filósofo franciscano Miguel Oromí Inglés (Sudanell, Segrià, 1911-Barcelona, 1974) ${ }^{10}$. Lo devolvió veintidós días después, pero la sorpresa fue que Oromí la autorizó "por tratarse de una obra de gran envergadura que se discutirá largo y tendido". Más permisivo, se avenía a publicarla introduciendo algunas mutilaciones, concretamente sobre el aborto.

Con un dictamen en contra y uno a favor condicionado, se solicitó una tercera opinión al padre Francisco Aguirre ${ }^{11}$. Entregado el 9 de septiembre de 1965, el informe de Aguirre es también negativo. Para asegurarse, se encargó un cuarto al padre Santos Beguiristain (Bell Ville, Argentina, 1908-Obanos, Navarra, 1994), falangista y doctor en Teolo-

\footnotetext{
${ }^{8}$ En líneas generales, había dos perfiles de censores: los más intelectuales, que incluían miembros de la iglesia, militares activos o en reserva y académicos, y los funcionarios del MIT. A menudo uno de los censores era un religioso.

${ }^{9}$ Informe de lectura mecanoscrito de Saturnino Álvarez Turienzo, fechado en Madrid el 1 de junio de 1965 (AGA 21-15951, exp. 10446).

${ }^{10}$ Informe de lectura mecanoscrito de Miguel Oromí Inglés, fechado en Madrid el 23 de junio de 1965 (AGA 21-16124, exp. 02681).

${ }^{11}$ Informe de lectura manuscrito de Francisco Aguirre, fechado en Madrid el 9 de septiembre de 1965 (AGA 21-16124, exp. 02681).
} 
gía y Derecho Canónico. El 10 de octubre de 1965 emitía un dictamen desfavorable ${ }^{12}$.

Emitida una resolución negativa para publicar la obra el 30 de septiembre de 1965, Edicions 62 presentó un recurso de alzada pidiendo una revisión del expediente ${ }^{13}$. Apeló al interés histórico, sociológico y filosófico de la obra, y a la relevancia de la autora. En especial hizo hincapié en la temática científica y especializada del ensayo y en el público reducido erudito a quien iba dirigida, estrategias a menudo utilizadas por las editoriales para minimizar el riesgo de que llegara en manos de un público amplio poco documentado. Sin embargo, el MIT reiteró la denegación.

Veintiún meses después de solicitar por primera vez la autorización para traducir El segon sexe, Edicions 62 presentó con la misma finalidad una nueva solicitud, que comportó la apertura en el MIT de un segundo expediente de censura. Se requirió de nuevo un informe al Álvarez Turienzo, que finalmente avaló la traducción. Desde la primera solicitud, del 7 de abril de 1965, habían pasado casi tres años.

\subsection{El expediente de censura de Una mort molt dolça (Une mort très douce) (1965)}

Armand Carabén envió la solicitud para traducir Una mort molt dolça el 30 de abril de 1965, veintitrés días después de que Edicions 62 tramitara la petición de El segon sexe. A diferencia del de Beauvoir, los trámites censores de esta traducción se llevaron a cabo sin contrariedades administrativas. El 10 de mayo el MIT solicitó una primera valoración al censor número 14, a quien no hemos podido identificar pero deducimos que era un religioso ${ }^{14}$. El censor etiqueta el libro de "duro y desgarrado como todos los de Simone de Beauvoir" y subraya que "sigue la línea clásica de esta escritora de hacer gala de su falta absoluta de Fe". Sin embargo, al final, lo autoriza.

\footnotetext{
${ }^{12}$ Informe de lectura manuscrito de P. Santos, fechado en Madrid el 10 de octubre de 1965 (AGA 21-16124, exp. 02681).

${ }^{13}$ Recurso de alzada mecanoscrito de Ramon Bastardes Porcel, fechado en Barcelona el 16 de octubre de 1965 (AGA 21-16124, exp. 02681).

${ }^{14}$ Informe de lectura mecanoscrito de autor no identificado, fechado en Barcelona el 17 de mayo de 1965 (AGA 21-16124, exp. 02681).
} 
Dos días después, se solicitó un segundo informe a Álvarez Turien$\mathrm{zo}^{15}$. En esos mismos días el censor tenía sobre la mesa dos informes: el de Una mort molt dolça, que autorizó el 26 de junio, y el de El segon sexe, que desautorizó cinco días más tarde. Su informe de Una mort molt dolça es contradictorio porque, desde el principio al final, los argumentos del censor apuntan a que no se debe autorizar el libro: "El libro, dentro de su brevedad, respira un tono inaceptable" y "La lectura puede ser perjudicial". Finalmente, "porque no deja de ser una obra 'de hecho' [...]. Con las debidas salvedades, puede autorizarse".

Fechada la resolución positiva el 2 de junio, la traducción salió en octubre de 1966 de la mano de Ramon Xuriguera. En el prólogo, coqueteando con las ideas de los censores, Xuriguera afirmaba al final: "Fiel a la verdad, como corresponde a la ética de la escritora, Una mort molt dolça, es un documento patético, un testimonio lúcido y corajudo" (1966: 11).

\subsection{Los expedientes de censura de Per una moral de l'ambigüitat} (Pour une morale de l'ambiguité) (1966) y Pyrrhus i Cineas (Pyrrhus et Cinéas) (1966)

E1 12 de julio de 1966 Edicions 62 envió al MIT dos solicitudes para traducir Per una moral de l'ambigüitat y Pyrrhus i Cineas (finalmente traducido por La mesura de l'home). Se trata de dos libros interrelacionados. En 1944 Beauvoir escribió Pyrrhus et Cinéas, donde debatía sobre la ética existencialista. Redactado tres años después, en 1947, Pour une morale de l'ambiguité es seguramente una de las obras más accesibles al pensamiento del existencialismo francés.

Consideradas dos partes de una misma filosofía, se presentaron las solicitudes juntas para ser publicadas en la misma colección de "Llibres a l'Abast" de Edicions 62. Se les adjudicó un número de registro correlativo: Per una moral de l'ambigüitat es el expediente 04753 y Pyrrhus $i$ Cineas es el 04754. Por lo tanto, evolucionaron administrativamente de manera paralela. Llegaron al MIT el mismo día (12 de julio), fueron adjudicadas en las mismas fechas a los mismos censores (13 de julio a Javier Dietta Pérez y 24 de septiembre a Saturnino Álvarez Turienzo),

\footnotetext{
${ }^{15}$ Informe de lectura mecanoscrito de Saturnino Álvarez Turienzo, fechado en Madrid el 26 de mayo de 1965 (AGA 21-17469, exp. 03340).
} 
ambas fueron retenidas sesenta días por el primer censor (estrategia habitual del MIT para entretener las peticiones de obras de autores disidentes) y, finalmente, obtuvieron la autorización el mismo día (14 de octubre). Sin embargo, por cuestiones de programación editorial, se publicaron con un año de diferencia.

Como en el caso de Per una moral de l'ambigüitat y Pyrrhus i Cineas, la mayoría de traducciones de autores consagrados de la colección de "Llibres a l'Abast", de Edicions 62, pasaron la censura por el supuesto interés minoritario que tenían. Mireia Sopena afirma que el MIT las autorizó "más por el imperativo de desacreditar una oposición dilatada y de vender una cara más amable a las potencias extranjeras que no por su magnanimidad" (2009: 416). Una vez descartado cualquier ataque al régimen nacional-católico, el tiraje limitado, el registro elevado y los tecnicismos de muchos de los volúmenes de la colección garantizaron, siempre con retoques y supresiones, las resoluciones favorables.

\subsection{El expediente de censura de El pensament polític de la dreta (Privilèges) (1968)}

El 3 de febrero de 1968 Edicions 62 cometió una gran audacia, por no decir temeridad. Sin pasar por consulta previa, presentó al MIT, en depósito, los ejemplares ya traducidos de la obra El pensament polític de la dreta, de Simone de Beauvoir, publicada en París en 1955, con grandes críticas a favor y en contra por su ataque a las ideología de la derecha contemporánea. Como ya hemos visto anteriormente, en 1966 el MIT, con el objetivo de incentivar una supuesta agilización de los trámites, creó un registro de las editoriales del país y les concedió un número con el cual podían enviar directamente a depósito los originales y las traducciones, que eran revisados y, si no contenían impropiedades según los parámetros del régimen, autorizados para su publicación. Como a Edicions 62 no se le confió número, este escarnio administrativo propició que casi nunca tuviera libros inmovilizados o aprobados por silencio administrativo. El caso que presentamos a continuación es la excepción de la regla.

Ante tal osadía, el aparato censor empezó a trabajar en diferentes niveles. El mismo día que llegó la solicitud, el 3 de febrero, se encargó un informe de lectura a uno de los censores más curtidos en la lucha por preservar las esencias patrióticas franquistas, el juez de profesión 
Francisco Fernández Jardón ${ }^{16}$. Fernández Jardón condena el libro y no le concede ni una oportunidad: "Por muy objetiva que pretende ser, aparentemente, la autora, no puede eludir consecuentemente el regar la propaganda comunista por diversos lugares". Por ello, y en conformidad con lo establecido en la Ley sobre Masonería y Comunismo del 1 de marzo de 1940, llega a la conclusión de que "no es aceptable el depósito y debe ser puesta la obra a disposición del referido Tribunal".

Como ya contemplaba la Ley de 1966 cuando se incurría en algún delito, el 5 de febrero, el mismo día que Fernández Jardón entregó el dictamen negativo, Carlos Robles Piquer, director general de Cultura Popular y Espectáculos, envió una carta con un ejemplar de dicha publicación y una copia del informe del censor al fiscal del Tribunal Supremo, Fernando Herrero Tejedor, para que considerara si el caso era denunciable ${ }^{17}$. Paralelamente, el MIT requirió otro informe de seguridad a Manuel Pui1 ${ }^{18}$, que entregó un día después secundando la decisión de Fernández Jardón.

Sorprendentemente, el mismo 6 de febrero Antonio Barbadillo, jefe de la Sección de Ordenación Editorial, emitió otro dictamen opuesto a los anteriores ${ }^{19}$. Pese a que la Ley de Represión de la Masonería y Comunismo "sanciona toda propaganda que exalte los principios o pretendidos beneficios del comunismo" y "sin despreciar la indudable peligrosidad social del libro", Barbadillo consideró que en la obra de Beauvoir no existía una apología clara e intencionada del comunismo. Por lo tanto, se inclinó por la libre difusión de la obra. Cuatro días después, el 10 de febrero, el fiscal Herrero Tejedor enviaba una carta amical a su colega Robles Piquer $^{20}$. Le comunicaba que, revisados los escritos, no consideraba procedente ejercitar ninguna acción penal.

Parece plausible pensar que, pese a que la obra fue denegada y denunciada, el régimen decidió no llevar a los tribunales a Edicions 62

\footnotetext{
${ }^{16}$ Informe de lectura mecanoscrito de Francisco Fernández Jardón, fechado en Madrid el 5 de febrero de 1968 (AGA 21-18726, exp. 00974).

${ }^{17}$ Carta mecanoscrita de Carlos Robles Piquer a Fernando Herrero Tejedor, fechada en Madrid el 5 de febrero de 1968 (AGA 21-18726, exp. 00974).

${ }^{18}$ Informe de lectura mecanoscrito de Manuel Pui, fechado en Madrid el 6 de febrero de 1968 (AGA 21-18726, exp. 00974).

${ }^{19}$ Dictamen firmado por el Jefe de la Sección de Ordenación Editorial, Antonio Barbadillo, fechado en Madrid el 6 de febrero de 1968 (AGA 21-18726, exp. 00974).

${ }^{20}$ Carta mecanoscrita de Fernando Herrero Tejedor a Carlos Robles Piquer, fechada en Madrid el 10 de febrero de 1968 (AGA 21-18726, exp. 00974).
} 
porque esta información hubiera llegado a la prensa extranjera y, en ese momento, la dictadura franquista quería ahorrarse cualquier toque de atención de las potencias internacionales. Aunque los censores de este expediente condensaron en su informe la fijación enfermiza que tenía el régimen contra el comunismo, la responsabilidad última fue de los superiores que priorizaron la política exterior del estado a la circulación de un libro proscrito. Finalmente, el expediente se resolvió por silencio administrativo.

\subsection{El expediente de censura de Les belles imatges (Les belles images) (1968)}

El 3 de abril de 1968 Aymà, con número de registro editorial, presentaba al MIT, en depósito, los seis ejemplares exigidos por la Ley de 1966 de Les belles imatges, de Simone de Beauvoir, novela publicada en París dos años antes. De la obra, de doscientas diez páginas, se había efectuado un tiraje de tres mil ejemplares, el doble de los que se realizaban normalmente con los ensayos.

Sin demora, al día siguiente, el MIT solicitaba un informe de lectura al censor Mampel, quien lo entregó dos días después con una resolución favorable ${ }^{21}$. Pese a no favorecer las ideas nacional-católicas, el censor consideraba que tampoco las criticaba: "Si bien aparece un ambiente arreligioso y costumbres contrarias a nuestra idiosincrasia, la novela tiene valores positivos: el amor a los hijos y al hogar". Cumplidos los requisitos de depósito y autorizada la obra, el 6 de abril, tres días después de presentar la instancia, el expediente fue resuelto positivamente.

\section{Conclusiones: ¿por qué Simone de Beauvoir en catalán?}

A partir de los años sesenta, por múltiples circunstancias que ya hemos analizado, las editoriales catalanas vivieron una etapa de dinamismo que se caracterizó por la variedad temática y la abundancia de títulos. En esa época, la traducción ocupó un papel primordial en la industria del libro. Francesc Vallverdú aporta datos concretos: durante la etapa

\footnotetext{
${ }^{21}$ Informe de lectura mecanoscrito de Mampel, fechado en Madrid el 5 de abril de 1968 (AGA 21-18865, exp. 02813).
} 
1962-68, de la producción total de libros en catalán, que sumó 2.831 ejemplares, se editaron más de mil traducciones, "un récord histórico" (2013: 13). En ese septenio, la traducción ocupó más del 38\% de la producción global, porcentaje altísimo comparado con otros países. El momento culminante fue en 1965, cuando un 55\% del total fueron traducciones. En esos mismos años, en castellano las traducciones representaban entre el $20 \%$ y el $30 \%$ de la producción; en danés el $20 \%$ $\mathrm{y}$, en otras lenguas, el 10\%.

Este contexto excepcional e irrepetible en la historia de la traducción (le siguió una fuerte crisis económica y editorial y, en 1973, las traducciones al catalán descendieron hasta un $8,3 \%$ ) propició más de un malentendido. Vallverdú narra una anécdota protagonizada por un periodista de Le Figaro Littéraire. Resulta que el corresponsal francés llegó a afirmar que la censura trataba con más severidad las traducciones al castellano que las mismas al catalán y lo intentó justificar alegando que en lengua catalana ya existían traducciones de Marx, Sartre y Gramsci, que no existían en lengua castellana (2013: 13). Estaba en lo cierto: en ese momento algunos autores eran traducidos antes al catalán que al castellano. Lo que ignoraba era que estos autores, prohibidos desde tiempos remotos por el franquismo en España, habían sido traducidos en América Latina porque los editores no tenían competidor editorial y habían comprado los derechos de reproducción al español.

Como Sartre (Godayol, 2015), el caso de Simone de Beauvoir es paradigmático de esta aparente paradoja. A pesar de los múltiples agravios y perjuicios de la censura, las seis traducciones al catalán de Beauvoir de los años sesenta fueron de las primeras en llegar a España, de las primeras en obtener la valoración positiva del MIT (solamente Todos los hombres son mortales (1956) y Djamila Bouchapa (1964) se habían traducido al español peninsular). Sin embargo, cuatro de ellas ya estaban traducidas al español argentino (algunos originales circulaban clandestinamente por el país). Cuatro editoriales diferentes de Buenos Aires compraron los derechos y las editaron: Psique publicó El segundo sexo en 1954; Schapie, Para una moral de la ambigüedad, en 1956; Leviatan, El pensamiento político de la derecha, en 1956; y La Pleyade, ¿Para qué la acción?, en 1972. De las cuatro, solamente se intentó importar en 1955 la traducción de El segundo sexo, que finalmente el 
MIT denegó ${ }^{22}$. Las dos restantes se trasladaron al español peninsular a finales de los años setenta y principios de los ochenta, coincidiendo con una etapa expansiva de la producción de libros vinculada al proceso de transición democrática de España. Ambas fueron editadas por la editorial barcelonesa Edhasa: Una muerte muy dulce en 1977, en versión de María Elena Vantillán, y Las bellas imágenes en 1981, en la de José Bianco.

El periodista de Le Figaro Littéraire solamente se había fijado en los datos cuantitativos y desconocía por completo cómo y de qué manera la censura maltrataba las traducciones en general y, en especial, las catalanas. El estudio de los expedientes de censura de las traducciones de Simone de Beauvoir pone de manifiesto unos casos representativos de la tipología de actuaciones que practicó la censura franquista durante la vigencia de la Ley de 1938 (1938-1966) y la de Ley de 1966 (1966-1976). De los seis expedientes analizados, los dos primeros se rigieron por la primera y los cuatro restantes por la segunda. De los dos primeros, uno fue desautorizado, incluido el recurso de revisión (El segon sexe), y el otro se aprobó sin incidencias al cabo de un mes (Una mort molt dolça). Pese a que la Ley de 1966 calculaba no más de treinta días hábiles para resolver las consultas, comprobamos, con los dos siguientes expedientes (Per una moral de l'ambigüetat y La mesura de l'home), que el tiempo entre la presentación de la solicitud y la autorización definitiva marcaba, en gran parte, las prevenciones que tenía el MIT de la autora y el título. Pasaron noventa y cinco días desde la fecha de entrada a su resolución. Los retuvieron tres meses sin justificación alguna. Corrió mejor suerte el último expediente de Beauvoir (Les belles imatges): teniendo en cuenta que la editorial Aymà disponía de número de registro, presentó directamente en depósito los ejemplares y, a los tres días, obtenía la autorización. Después del expediente de $E l$ segon sexe, el más complejo y curioso es el de El pensament polític de la dreta, aprobado por silencio administrativo, pudiendo ser secuestrado, después de veinticuatro días de ser solicitada su autorización.

Por considerarse una autora extranjera controvertida, los informes de lectura de Beauvoir se delegaron, mayoritariamente, a académicos reputados afines al régimen. Destaca el padre Saturnino Álvarez Tu-

${ }^{22}$ Informe de lectura mecanoscrito de Saturnino Álvarez Turienzo, fechado en Madrid el 6 de marzo de 1965 (AGA 21-15951, exp. 1349). 
rienzo, censor en cuatro de los seis expedientes de la autora. De entrada, Beauvoir se consideró una bestia negra, pero, a medida que pasaban los meses, no se constriñó más porque llegó un momento que su notoriedad internacional la protegió mínimamente de persecuciones ideológicas. No le convenía al régimen recibir denuncias de la oposición interior o de la prensa extranjera ni corroborar que se perseguían autores contemporáneos consagrados. Asimismo, la especialización temática y el tiraje reducido favorecieron la aprobación de sus traducciones.

Para acabar, porque la traducción no es neutra ni objetiva y porque detrás de cada título escogido hay un quién, un o unos mecenas, hay que referirse al principal responsable de que Simone de Beauvoir se convirtiera en una de las autoras francesas más traducidas al catalán en los años sesenta: el editor, recientemente fallecido, Josep Maria Castellet (Barcelona, 1926-2014). Castellet fue el promotor directo de cuatro de sus traducciones y el agitador del caldo de cultivo del pensamiento existencialista en Cataluña. A temprana edad, se infectó rápido del virus sartriano y beauvoriano. En diciembre de 1949, con veintitrés años, acabado de publicar en Francia, escribió una reseña incendiaria de $L e$ deuxième sexe en la revista profalangista Estilo, que conllevó que ese número fuera retirado y el autor sancionado y apartado de la publicación. En él denunciaba la situación de la mujer en España y pedía su participación en la vida pública. Esperó veinte años y, cuando llegó la ocasión, luchó incondicionalmente por recuperar el tiempo perdido y ofrecer las obras de Simone de Beauvoir al público catalán.

\section{Bibliografía}

Abellán, Manuel L. 1980. Censura y creación literaria en España (19391976). Barcelona: Ediciones Península.

Bacardí, Montserrat. 2012. La traducció catalana sota el franquisme. Lleida: Punctum.

Bacardí, Montserrat \& Godayol, Pilar (ed.). 2011. Diccionari de la traducció catalana. Vic: UAB, UJI, UIB, UVic \& Eumo Editorial.

Castellet, Josep Maria. 1949 ( 5 de diciembre). Le deuxième sexe. Estilo 8-9.

Cisquella, Georgina; Erviti, José Luis \& Sorolla, José A. 2002. La represión cultural en el franquismo. Diez años de censura de libros durante la Ley de Prensa (1966-1976). Barcelona: Anagrama.

Cornellà-Detrell, Jordi. 2010. Traducció i censura en la represa cultural dels anys 1960. L'Avenç 359: 44-51. 
Cornellà-Detrell, Jordi. 2013. L'auge de la traducció en llengua catalana als anys 60: el desglaç de la censura, el XVI Congreso Internacional de Editores i el problema dels drets d'autor. Quaderns. Revista de Traducció 20: 47-67.

Gallofré, M. Josepa. 1991. L'edició catalana i la censura franquista (19391951). Barcelona: Publicacions de l'Abadia de Montserrat.

Godayol, Pilar. 2013a. Censure, féminisme et traduction: Le Deuxième sexe de Simone de Beauvoir en catalan. Nouvelles Questions Feministes 32(2): 74-88.

Godayol, Pilar. 2013b. Simone de Beauvoir en català. Bulletin Hispanique 115(2): 669-684.

Godayol, Pilar. 2014. Feminism and translation in the 60s: the reception in Catalunya of Betty Friedan's The Feminine Mystique. Translation Studies 7(3): 267-283.

Godayol, Pilar, 2015. The Francoist censorship and the Catalan translations of Jean-Paul Sartre. Perspectives. Studies in Translatology. En prensa.

Gutierrez-Lanza, Camino. 1997. Leyes y criterios de censura en la España Franquista: Traducción y recepción de textos literarios. En Vega, Miguel-Angel \& Martín-Gaitero, Rafael (ed.). La palabra vertida. Investigaciones en torno a la Traducción. Madrid: Editorial Complutense, 283-290.

Llanas, Manuel. 2006. L'edició a Catalunya: el segle XX (1939-1975). Barcelona: Gremi d'Editors de Catalunya.

Merino, Raquel. 2008. Traducción y censura en España (1939-1985). Estudios sobre corpus TRACE: cine, narrativa, teatro. Bilbao: Universidad del País Vasco/Universidad de León.

Moret, Xavier. 2002. Tiempo de editores. Historia de la edición en España, 1939-1975. Barcelona: Destino.

Sopena, Mireia. 2013. Con vigilante espíritu crítico. Els censors en les traduccions assagístiques d'Edicions 62. Quaderns. Revista de Traducció 20: 147-161.

Triadú, Joan. 1968. Novel·la extranjera en català. Després d'una generació sense traduccions. Serra d'Or 106 (marzo): 39-41.

Vallverdú, Francesc. 1987. Edicions 62. Vint-i-cinc anys (1962-1987). Barcelona: Proa.

Vallverdú, Francesc. 2013. La traducció i la censura franquista: la meva experiència a Edicions 62. Quaderns. Revista de Traducció 20: 9-16.

Vandaele, Jeroen. 2010. It Was What it Wasn't: Translation and Francoism. En Rundle, Christopher \& Sturge, Kate (ed.). Translation under fascim. Basingstoke: Palgrave Macmillan, 84-116. 


\section{Traducciones de Simone de Beauvoir al catalán}

Beauvoir, Simone de. 1966. Una mort molt dolça. Barcelona: Aymà. [Prólogo y traducción de Ramon Xuriguera].

Beauvoir, Simone de. 1968. El pensament politic de la dreta. Barcelona: Edicions 62. [Traducción de Jordi Solé-Tura].

Beauvoir, Simone de. 1968. Les belles imatges. Barcelona: Aymà. [Prólogo y traducción de Joan Oliver].

Beauvoir, Simone de. 1968. Per una moral de l'ambigüitat. Barcelona: Edicions 62. [Traducción de Jordi Solé-Tura].

Beauvoir, Simone de. 1968. El segon sexe. I y II. Barcelona, Editorial 62. [Prólogo de Maria Aurèlia Capmany. Traducción de Hermínia Grau y Carme Vilaginés].

Beauvoir, Simone de. 1969. La mesura de l'home. Barcelona: Edicions 62. [Traducción de Miquel Martí i Pol].

Beauvoir, Simone de. 2002. La dona trencada. Barcelona: Deriva. [Traducción de Marta Pessarrodona].

Beauvoir, Simone de. 2009. Ningú no neix dona. Antologia de textos d'El segon sexe, de Simone de Beauvoir. Marta Segarra, ed. Vic: Eumo. [Traducción de Hermínia Grau y Carme Vilaginés]. 